\title{
Effect of manually assisted cough and mechanical insufflation on cough flow of normal subjects, patients with chronic obstructive pulmonary disease (COPD), and patients with respiratory muscle weakness
}

\author{
P Sivasothy, L Brown, I E Smith, J M Shneerson
}

\begin{abstract}
Background-It has been suggested that cough effectiveness can be improved by assisted techniques. The effects of manually assisted cough and mechanical insufflation on cough flow physiology are reported in this study.

Methods-The physiological actions and patient self-assessment of manually assisted cough and mechanical insufflation were investigated in 29 subjects (nine normal subjects, eight patients with chronic obstructive pulmonary disease (COPD), four subjects with respiratory muscle weakness (RMW) with scoliosis, and eight subjects with RMW without scoliosis).

Results-The peak cough expiratory flow rate and cough expiratory volume were not improved by manually assisted cough and mechanical insufflation alone or in combination in normal subjects. The median increase in peak cough expiratory flow in subjects with RMW without scoliosis with manually assisted cough alone or in combination with mechanical insufflation of $84 \mathrm{1} / \mathrm{min}$ ( $95 \%$ confidence interval (CI) 19 to 122$)$ and $144 \mathrm{1} / \mathrm{min}(95 \%$ CI 14 to 195), respectively, reflects improvement in the expulsive phase of coughing by these techniques. Manually assisted cough and mechanical insufflation in combination raised peak expiratory flow rate more than either technique alone in this group. The abnormal chest shape in scoliotic subjects and the fixed inspiratory pressure used made effective manually assisted cough and mechanical insufflation difficult in this group and no improvements were found. In patients with COPD manually assisted cough alone and in combination with mechanical insufflation decreased peak expiratory flow rate by $144 \mathrm{1} / \mathrm{min}(95 \%$ CI 25 to 259$)$ and $1351 / \mathrm{min}$ (95\% CI 30 to 312), respectively.

Conclusions-Manually assisted cough and mechanical insufflation should be considered to assist expectoration of secretions in patients with RMW without scoliosis but not in those with scoliosis.

(Thorax 2001;56:438-444)
\end{abstract}

Keywords: manually assisted cough; mechanical insufflation; cough flow physiology; chronic obstructive pulmonary disease; respiratory muscle weakness; scoliosis
Cough is an important part of the airway defence aiding the removal of secretions. ${ }^{1}$ It has three components - an inspiratory phase consisting of inhalation to greater than resting end inspiratory volume; a compressive phase comprising glottic closure accompanied by an increased intrathoracic pressure as a result of expiratory muscle contraction; and an expulsive phase resulting from sudden glottic opening. ${ }^{2}$ The high air flow velocities in the expulsive phase transfer kinetic energy from air to the secretions or foreign bodies, shearing them off the bronchial wall and transporting them to the pharynx or mouth.

Neuromuscular disorders such as amyotrophic lateral sclerosis, ${ }^{3}$ poliomyelitis, ${ }^{4}$ myasthenia gravis, ${ }^{5}$ and muscular dystrophies ${ }^{6}$ can impair any of these three phases. In pulmonary disorders such as chronic bronchitis and emphysema the reduced expiratory flow resulting from dynamic airway compression and increased viscosity of bronchial secretions is probably the main cause of cough ineffectiveness. $^{7}$

Several methods of assisting the expulsive phase of coughing have been proposed. ${ }^{89} \mathrm{We}$ have examined the efficacy of manually assisted cough and mechanical insufflation on cough dynamics in normal subjects, patients with chronic obstructive pulmonary disease (COPD), and those with respiratory muscle weakness with and without scoliosis.

\section{Methods}

SUBJECTS

We studied normal volunteers and patients suffering from respiratory muscle weakness (RMW) due to neuromuscular disorders and those with chronic obstructive pulmonary disease (COPD). All normal subjects were non-smokers without a history of respiratory, neuromuscular, or cardiovascular disease. Respiratory muscle weakness was defined as static inspiratory and expiratory maximal mouth pressures $<70 \%$ predicted. Subjects with RMW were subdivided according to whether or not they had a thoracic scoliosis. Scoliosis was diagnosed on physical examination and from spinal radiographs with a Cobb angle of $>70^{\circ}$. All cases of RMW had been diagnosed by a neurologist and had no other respiratory disease. All patients with COPD fulfilled the 
American Thoracic Society criteria. ${ }^{10}$ All subjects gave informed consent prior to participation in the study.

Nine normal subjects, eight with COPD, and 12 with RMW were studied. The RMW group without scoliosis comprised seven subjects with amyotrophic lateral sclerosis and one with Becker's muscular dystrophy. There were two subjects with previous poliomyelitis, one with Duchenne's muscular dystrophy, and one with spinal muscular atrophy who had scoliosis on spinal radiographs.

STUDY DESIGN

Forced expiratory volume in one second $\left(\mathrm{FEV}_{1}\right)$, forced vital capacity (FVC), and maximal voluntary ventilation (MVV) were measured using a pneumotachograph spirometer (Vitalograph, Buckingham, UK) and total lung capacity (TLC) was measured using body plethysmography (Masterlab, Jaeger, Wurzburg, Germany). Maximum mouth inspiratory (PImax) and expiratory (PEmax) pressures were measured with a hand held myometer (P K Morgan, Gillingham, Kent, UK). PImax was measured at residual volume and Pemax was measured at TLC with the cheeks held. Subjects performed these manoeuvres until a reproducible maximal effort was achieved. All values were expressed as raw data and percentage predicted values. ${ }^{11} 12$

Cough evaluation was performed using a modification of a method previously described. ${ }^{13}$ A face mask (Hans Rudolf) was attached directly to a $4.5 \mathrm{~cm}$ pneumotachograph (P K Morgan) from which the peak cough expiratory flow and cough expiratory volume were derived using an electronic transducer and integrator. The pneumotachograph had a linear response up to $900 \mathrm{l} / \mathrm{min}$ and a response time of $<5 \mathrm{~ms}$. All data were recorded digitally with an analogue to digital converter onto an IBM compatible computer using the CARDAS data logging system (Oxford Medical Sciences, Oxford, UK). The cough expiratory volume and peak cough expiratory flow were defined as the maximal volume and flow recorded, respectively (fig $1 \mathrm{~A}$ and $\mathrm{B}$ ). The time from onset of expiratory flow to peak cough expiratory flow, the peak value time, was measured (fig 1B). The system was calibrated between subjects for flow using a rotameter, range $0-450$ 1/min (Si-plan Electronics $\mathrm{Re}-$ search, Stratford on Avon, UK) and for volume using a 1 litre calibration syringe ( $\mathrm{P} K$ Morgan).

Oesophageal and gastric pressures were measured to estimate pleural and abdominal pressures during coughing using balloons (P K Morgan) connected to a differential pressure transducer (Si-plan Electronics Research). The data were recorded onto a paper chart recorder (Dash 3, Astromed, Warwick, RI, USA). The nasopharynx was anaesthetised with topical lidocaine before the balloons were inserted. Baseline cough evaluation was performed in subjects before and after passage of balloons. Subjects undergoing oesophageal manometry had fasted prior to the investigation.
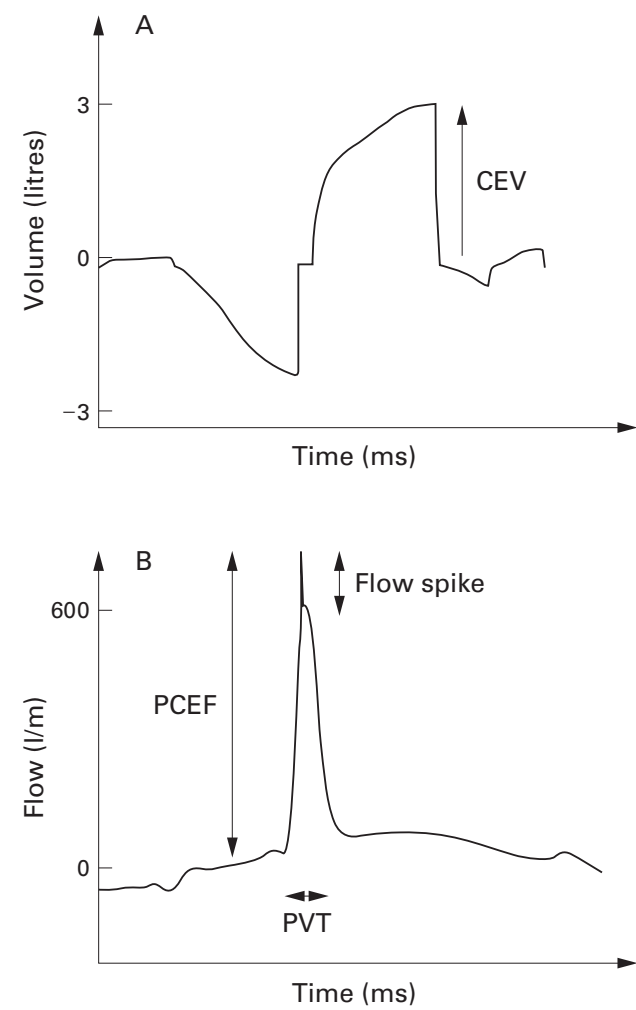

Figure 1 Normal recordings of $(A)$ cough expiratory volume $(C E V)$ and $(B)$ cough expiratory flow. The peak cough expiratory flow rate (PCEF) was measured from the initiation of a positive flow rate to the maximum obtained value. This included the flow spike if present. The peak value time (PVT) was measured as the time taken from initiation of a positive flow rate to the PCEF. The cough expiratory flow volume was taken as the maximum expiratory volume recorded.

The cough manoeuvre was performed with the subjects in a semirecumbent position. It consisted of inspiration to near TLC followed by a maximal voluntary cough. All subjects practised coughing while the face mask was adjusted to minimise air leaks. An investigator held the subject's cheeks during the cough manoeuvres. Subjects were asked to perform three consistent coughs as baseline values prior to evaluation of assisted cough techniques. Consistent coughs were defined as peak cough expiratory flows that did not vary by more than $15 \%$.

Manually assisted cough was performed by an experienced physiotherapist. It consisted of manual thoracoabdominal compression during the expulsive phase of a maximal voluntary cough. Hand positions during thoracoabdominal compression were optimised for patients with scoliosis by placing the hand used for thoracic compression on the hyperflated hemithorax. Mechanical insufflation was performed with an In-exsufflator (J H Emerson Co, Cambridge, MA, USA) set to give $20 \mathrm{~cm} \mathrm{H}_{2} \mathrm{O}$ inspiratory and $-20 \mathrm{~cm} \mathrm{H}_{2} \mathrm{O}$ expiratory pressure. Two In-exsufflator cycles were used to aid inflation and deflation of the thorax and after a third inspiration the subject was asked to make a maximal voluntary cough without the aid of negative pressure. All subjects practised with both manually assisted cough and mechanical 
Table 1 Baseline comparison of lung function and respiratory muscle assessment

\begin{tabular}{lllll}
\hline & & & \multicolumn{2}{l}{ Neuromuscular weakness } \\
\cline { 4 - 5 } & $\begin{array}{l}\text { Normal subjects } \\
(n=9)\end{array}$ & $\begin{array}{l}\text { COPD } \\
(n=8)\end{array}$ & $\begin{array}{l}\text { Without scoliosis } \\
(n=8)\end{array}$ & $\begin{array}{l}\text { With scoliosis } \\
(n=4)\end{array}$ \\
\hline Age (years) & $27(17-71)$ & $65(52-74)$ & $63(27-73)$ & $57(44-66)$ \\
Sex & $4 \mathrm{M}, 5 \mathrm{~F}$ & $3 \mathrm{M}, 5 \mathrm{~F}$ & $8 \mathrm{M}$ & $3 \mathrm{M}, 1 \mathrm{~F}$ \\
FEV $_{1}(1)$ & $3.8(1.7-4.2)$ & $0.95(0.35-1.1)$ & $0.73(0.48-1.8)$ & $0.8(0.65-1.25)$ \\
FEV (\% pred) & $98(88.3-120.1)$ & $37(13.4-44.2)$ & $19(13.6-43.9)$ & $33(28.4-40.4)$ \\
FVC (1) & $4.6(2.1-5.9)$ & $1.8(0.77-2.75)$ & $0.83(0.55-1.57)$ & $1.5(0.7-1.75)$ \\
FVC (\% pred) & $100(78.3-120.8)$ & $66(24.5-84.9)$ & $18(13-42.0)$ & $35(15-42.9)$ \\
PEFR (1/min) & $444(410-633)$ & $212(110-270)$ & $123(68-150)$ & $225(220-240)$ \\
PEFR (\% pred) & $103(86.9-140)$ & $51(24.9-66.7)$ & $24(13.1-31.9)$ & $47(45.7-66.7)$ \\
PImax (cm $\left.\mathrm{H}_{2} \mathrm{O}\right)$ & $99(59-137)$ & $37(18-91)$ & $15(11-22)$ & $37(30-49)$ \\
PImax (\% pred) & $115(87-151)$ & $44(18.5-93.3)$ & $14(11.9-24.9)$ & $41(37.6-50.7)$ \\
PEmax (cm H $\left.\mathrm{H}_{2} \mathrm{O}\right)$ & $126(104-239)$ & $84(52-167)$ & $22(16-35)$ & $51(17-62)$ \\
PEmax (\% pred) & $118(83-228)$ & $94(74.7-194.3)$ & $19(11.7-27.6)$ & $42(36.4-67.3)$ \\
MVV (1/min) & $128(75-195)$ & $33(19-60)$ & $26(16-35)$ & $33(21-44)$ \\
MVV (\% pred) & $107(71-115)$ & $32(16.7-66.1)$ & $17(11.1-27.8)$ & $24(17.0-33.8)$ \\
\hline
\end{tabular}

Data are expressed as median (range).

$\mathrm{FEV}_{1}=$ forced expiratory volume in one second; FVC = forced vital capacity; PEFR = peak expiratory flow rate; PImax, Pemax $=$ maximum inspiratory and expiratory pressure; $M V V=$ maximum voluntary ventilation. insufflation prior to the investigations. Familiarisation with the techniques took no more than five practice coughs with each manoeuvre. At least 5 minutes elapsed between each cough attempts of each was analysed. was randomised for each subject. At the end of the treatment, subjects were asked whether each assisted cough technique had aided, impaired, or had no effect on their cough and to rank them in order of perceived effectiveness.

STATISTICAL ANALYSIS

Statistical analysis was performed using SPSS software for Windows (SPSS, Chicago, USA). The Mann-Whitney/Wilcoxon rank sum test was used to compare predicted pulmonary function test data with observed data for the normal subjects with those with COPD and
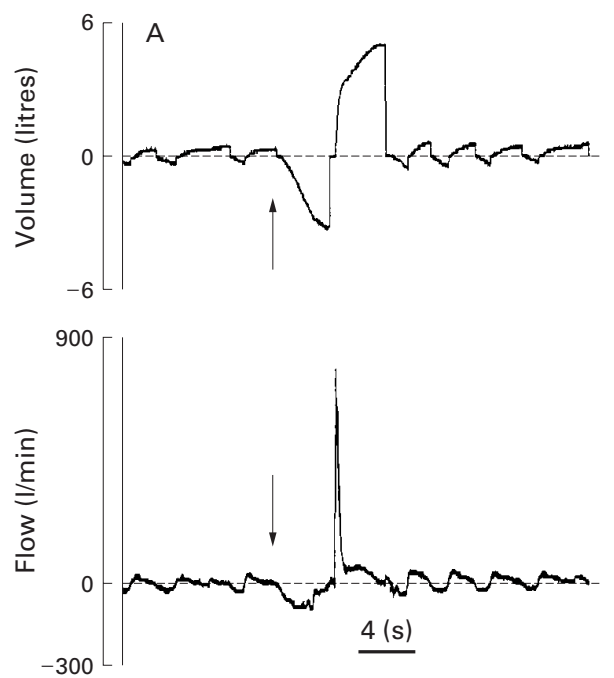
manoeuvre and the best result of at least three

To exclude bias the order of the treatments

those with respiratory muscle weakness, with and without scoliosis. It was also used to compare the pulmonary function data between patients with RMW with and without scoliosis. The Wilcoxon matched pairs signed rank test was used to investigate the effect of different techniques (mechanical insufflation, manually assisted cough, and in combination) on peak cough expiratory flow, cough expiratory volume, and peak value time. Analyses of order of cough manoeuvres on results was made using the Friedman test. Statistical significance was taken as $\mathrm{p}<0.05$. The Bonferroni adjustment was used to correct for repeat pairwise comparisons.

\section{Results}

Data for age, sex, and pulmonary function of the four subject groups in this study are shown in table 1 . The lung volumes of the normal subjects were not significantly different from predicted values. Those with COPD had a median $\mathrm{FEV}_{1} / \mathrm{FVC}$ of only $44 \%$ (range 21.0 68.9) and a significantly increased TLC, a reduced Pimax, normal PEmax, and reduced MVV. Subjects with RMW with and without scoliosis had a significantly reduced $\mathrm{FEV}_{1}$, FVC, PImax, Pemax, and MVV compared with predicted values and those without scoliosis had a significantly lower $\mathrm{FEV}_{1}$, peak expiratory flow rate (PEFR), PImax, PEmax, and MVV than those who did not.

In normal subjects the digital recordings of flow during a cough revealed a sharp upstroke in flow with a transient flow spike followed by a gradual fall and finally a more rapid declining phase (fig 2A). Peak cough expiratory flow was higher than PEFR. The cough expiratory volume was lower than the $\mathrm{FEV}_{1}$.

In the presence of RMW the upstroke of the cough flow rate was considerably reduced and
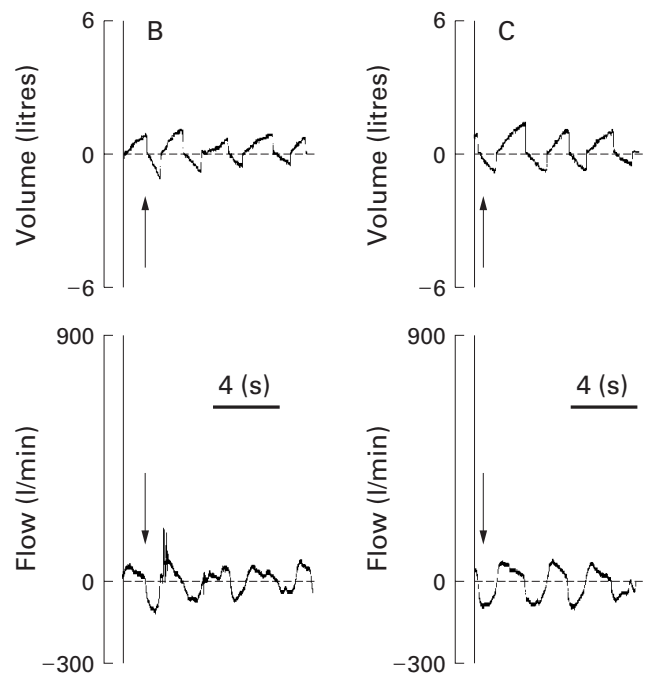

Figure 2 Typical flow and volume recordings before and during a maximum voluntary cough manoeuvre in $(A)$ normal subjects, $(B)$ patients with COPD, and $(C)$ patients with respiratory muscle weakness without scoliosis. All recordings are shown on the same volume, flow, and time scale for comparison. The upper recording shows changes in inspiratory and expiratory volumes with time and the lower recording shows changes in flow with time. Arrows indicate the initiation of a maximal voluntary cough. Normal subjects were able to generate a large cough expiratory volume and peak cough expiratory flow with a large cough flow spike; patients with COPD were able to generate a small cough flow spike but were unable during a cough to generate cough expiratory volumes; patients with respiratory muscle weakness without scoliosis were typically unable to generate an expiratory flow spike or, if they were produced, they were greatly diminished in magnitude. The baseline flow and volume recordings of subjects with respiratory muscle weakness were similar whether or not scoliosis was present. 
Table 2 Peak cough expiratory flow rate (PCEF), cough expiratory volume (CEV), and peak value time (PVT) in subjects during the various assisted cough techniques

\begin{tabular}{lllll}
\hline & & & Neuromuscular weakness \\
\cline { 5 - 5 } & Normal subjects $(n=9)$ & COPD $(n=8)$ & Without scoliosis $(n=8)$ & With scoliosis $(n=4)$ \\
\hline Baseline & & & & $288(175-367)$ \\
PCEF (1/min) & $668(310-700)$ & $370(267-483)$ & $104(43-188)$ & $0.9(0.50-1.1)$ \\
CEV (1) & $2.4(1.31-4.91)$ & $1.02(0.4-2.51)$ & $0.5(0.3-0.8)$ & $44(40-50)$ \\
PVT (ms) & $35(30-45)$ & $32(25-40)$ & $80(40-220)$ & $193(185-287)$ \\
Manually assisted cough & & & & $0.5(0.41-1.01)$ \\
PCEF (1/min) & $624(326-700)$ & $226(120-315)^{\star}$ & $185(93-355)^{\star}$ & $50(35-55)$ \\
CEV (1) & $2.91(1.31-5.31)$ & $0.8(0.20-1.51)$ & $0.7(0.31-1.07)$ & $231(148-597)$ \\
PVT (ms) & $50(40-85)^{\star \star}$ & $45(30-60)^{\star}$ & $118(35-360)^{\star}$ & $0.7(0.3-1.3)$ \\
Mechanical insufflation & & & & $45(30-60)$ \\
PCEF (1/min) & $676(494-695)$ & $288(218-370)$ & $156(61-247)$ & $362(218-440)$ \\
CEV (1) & $2.2(0.8-5.91)$ & $0.45(0.2-0.91)^{\star}$ & $0.6(0.3-1.61)$ & $0.6(0.4-1.01)$ \\
PVT (ms) & $35(30-40)$ & $33(30-40)$ & $85(20-420)$ & $50(45-120)$ \\
In combination & & & & $248(110-343)^{\star}$ \\
PCEF (1/min) & $624(288-695)$ & $245(218-370)^{\star}$ & $0.6(0.40-2.19)$ & $75(20-420)$ \\
CEV (1) & $2.2(0.7-5.41)$ & $0.8(0.3-1.00)$ & & \\
PVT (ms) & $55(40-100)$ & $40(35-50)$ & &
\end{tabular}

Data are expressed as median (range).

${ }^{\star} \mathrm{p}<0.01$.

the transient flow spike was reduced or absent (fig 2C). There was also a shorter declining phase. Peak cough expiratory flow was higher than PEFR and the cough expiratory volume was lower than the $\mathrm{FEV}_{1}$. The peak value time was significantly longer in the RMW group without scoliosis than in any of the other groups.

In those with COPD the transient flow spike had a rapidly declining phase similar to normal subjects (fig 2B) but the peak cough expiratory flow was significantly lower in COPD. No difference was found in the cough expiratory volume compared with the $\mathrm{FEV}_{1}$ in patients with COPD.

The order in which the assisted cough manoeuvres were performed did not have a significant effect on the peak cough expiratory flow, cough expiratory volume, and peak value time. There were no discernible changes in baseline values of peak cough expiratory flow and cough expiratory volume with the various assisted cough manoeuvres in normal subjects (table 2) but there was a significant rise in the peak value time with manually assisted cough compared with baseline.

Those with RMW without scoliosis had a significant rise in peak cough expiratory flow with manually assisted cough alone and in combination with mechanical insufflation compared with baseline (fig 3). The peak value time with manually assisted cough was also significantly prolonged compared with baseline. No significant changes in peak cough expiratory flow, cough expiratory volume, or peak value time were noted with mechanical insufflation compared with baseline in this group.

In patients with RMW with scoliosis there were no significant changes in peak cough expiratory flow, cough expiratory volume, and peak value time compared with baseline with any of the three assisted cough manoeuvres. An example of the effects of the assisted cough manoeuvres on normal subjects, patients with COPD, and those with RMW without scoliosis on the flow recordings are shown in fig 3.

In patients with COPD there was a significant deterioration in peak cough expiratory flow compared with baseline with manually

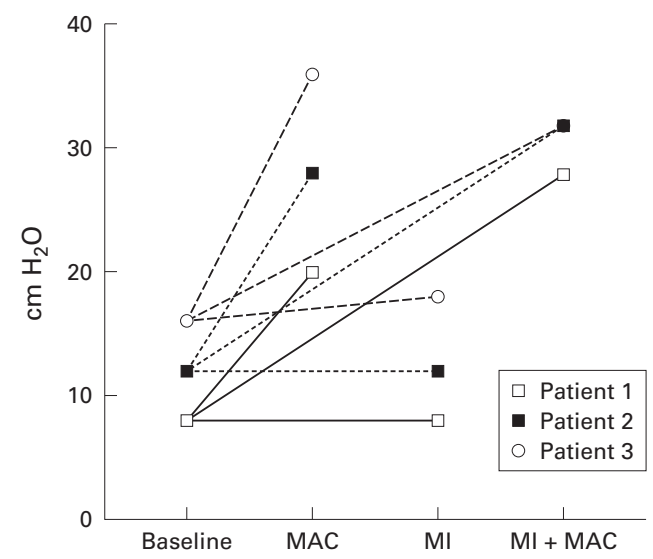

Figure 3 Effect of manually assisted cough (MAC), mechanical insufflation (MI), and both techniques in combination $(M I+M A C)$ on oesophageal pressures during cough in comparison with baseline voluntary coughing.

assisted cough alone, mechanical insufflation alone, and in combination. The median cough expiratory volume fell with mechanical insufflation from 1.021 to 0.451 . There was also a significant increase in the peak value time with manually assisted cough alone over baseline values in subjects with COPD.

Oesophageal pressures during coughing in normal subjects and those with COPD exceeded $100 \mathrm{~cm} \mathrm{H}_{2} \mathrm{O}$, at which pressure the balloons collapse. This made analysis of the values difficult to interpret. The three subjects with RMW all had oesophageal pressures of $<50 \mathrm{~cm} \mathrm{H}_{2} \mathrm{O}$. None had a significantly different peak cough expiratory flow, cough expiratory volume, or peak value time when baseline values were compared with values following balloon insertion. In these subjects with RMW manually assisted cough increased the oesophageal pressure (fig 3). No additional increase in the oesophageal pressure was seen when manually assisted cough was used in combination with mechanical insufflation.

Subjects with COPD reported no improvement with manually assisted cough and they felt mechanical insufflation alone and in combination with manually assisted cough made their cough less effective. In those with RMW without scoliosis manually assisted 
Table 3 Comparisons of previous cough augmentation studies

\begin{tabular}{|c|c|c|c|c|c|c|c|c|}
\hline Study & Year & Subjects & $n$ & Apparatus & Cough adjunct & $\begin{array}{l}F E V_{1} \text { (l or } \% \\
\text { predicted) }\end{array}$ & $\begin{array}{l}\text { CEFR } \\
(\text { (l/min) }\end{array}$ & Poes \\
\hline \multirow[t]{4}{*}{ Present } & 2001 & Normal & 9 & Pneumotachograph & MAC & $3.80(98 \%)$ & 668 & \\
\hline & & COPD & 8 & Poes and Pabd & MI & $0.95(37 \%)$ & 370 & \\
\hline & & RMW with scoliosis & 4 & & $\mathrm{MAC}+\mathrm{MI}$ & $0.73(19 \%)$ & 104 & $12^{\star \star \star}$ \\
\hline & & RMW without scoliosis & 8 & & & $0.80(33 \%)$ & 288 & \\
\hline \multirow[t]{3}{*}{ Barach et $a l^{17}$} & 1953 & Normal & 15 & Differential pressure ${ }^{\star}$ & ME & NA & 465 & NA \\
\hline & & COPD & 19 & & & & 251 & \\
\hline & & Polio & 1 & & & & $<180$ & \\
\hline \multirow[t]{4}{*}{ Barach et al ${ }^{6}$} & 1954 & COPD & 53 & Mask pressures & ME & NA & NA & NA \\
\hline & & Polio & 12 & & & & & \\
\hline & & Postoperative & 8 & & & & & \\
\hline & & Bronchiectasis & 23 & & & & & \\
\hline \multirow{2}{*}{ Bickerman $e t a l^{4}$} & 1958 & Normal & 18 & Pneumotachograph & Isoproterenol & NA & 409 & NA \\
\hline & & Asthma & 25 & & & & 187 & \\
\hline \multirow[t]{2}{*}{ Kirby et $a l^{18}$} & 1966 & Tetraplegics & 12 & Wedge spirometer & $\begin{array}{l}\mathrm{MI}\left(50 \mathrm{~cm} \mathrm{H}_{2} \mathrm{O}\right) \\
\mathrm{MAC}\end{array}$ & 1.85 litres & 218 & NA \\
\hline & & & & & Abdominal binders & & & \\
\hline \multirow[t]{4}{*}{ Leiner $e t a l^{14}$} & 1966 & Normal & 25 & Wright peak flow meter & Isoproterenol & $85.6 \%$ & 597.2 & NA \\
\hline & & Obstructive & 40 & & & $56.7 \%$ & 320.9 & \\
\hline & & Restrictive & 22 & & & $77.0 \%$ & 387.3 & \\
\hline & & Combined restrictive & 50 & & & $47.8 \%$ & 175.5 & \\
\hline \multirow[t]{2}{*}{ Loudon et $a l^{19}$} & 1967 & Normal & 9 & Pneumotachograph & Maximal voluntary cough & 3.9 litres & 672 & 167.3 \\
\hline & & COPD & 9 & Poes & & 1.1 litres & 288 & 153.2 \\
\hline \multirow[t]{2}{*}{ Langlands et $a l^{20}$} & 1967 & Normal & 10 & Pneumotachograph & $30 \%$ citric acid & 3.3 litres & 487 & 147 \\
\hline & & COPD & 10 & Poes and Pabd & & 1.4 litres & 165 & 180 \\
\hline & 1993 & Neuromuscular & 46 & Peak flow meter & MI-E & 0.44 & 104 & \\
\hline \multirow[t]{2}{*}{ Bach $e^{a l^{16}}$} & 1995 & ALS & $50(27$ & Peak flow meter & MI-E & $0.73^{\star \star}$ & 276 & NA \\
\hline & & & $\begin{array}{l}\text { successfully } \\
\text { treated) }\end{array}$ & & MAC & $0.93^{\star \star}$ & 150 & \\
\hline
\end{tabular}

$\mathrm{COPD}=$ chronic obstructive pulmonary disease ALS $=$ amyotrophic lateral sclerosis $;$ Poes $=$ oesophageal pressure Pabdo $=$ gastric pressure $;$ MI $=$ mechanical insuf flation; MI-E = mechanical insufflation and exsufflation; $M A C=$ manually assisted cough; $\mathrm{ME}=$ mechanical exsufflation; $\mathrm{GPB}=$ glossopharyngeal breathing. ${ }^{\star}$ Unable to record less than $1801 / \mathrm{min}$.

${ }^{\star \star}$ Sitting vital capacity within 3 months of initial ventilator use (second value is that of unsuccessfully treated subjects).

$\star \star \star$ Value for three subjects with respiratory muscle weakness (two without and one with scoliosis).

cough alone and in combination with mechanical insufflation improved cough clearance but mechanical insufflation alone had no effect. Subjects with RMW with scoliosis did not report a benefit from any of the assisted cough manoeuvres.

\section{Discussion}

In this study we have investigated the effect of manually assisted cough and mechanical insufflation alone and in combination in the presence of COPD, and RMW with and without scoliosis, looking for the first time at their effect on peak value time and cough expiratory volume in addition to peak cough expiratory flow. Cough flow and assisted cough techniques have been studied for over 40 years. During this period several assisted techniques have been evaluated in different subject groups (table 3) but in each study there has been a problem in the recording of peak cough expiratory flow.

Our study overcame difficulties encountered in other studies by measuring peak cough expiratory flow using a pneumotachograph linked to a digital recorder which was linear in response with regard to flow, volume, and time over the investigated data range. Other investigators have used an adapted Wright peak flow meter to measure peak cough expiratory flow but this only measures the peak expiratory flow maintained for $10 \mathrm{~ms}$ and fails to record the transient flow spikes so that recorded peak cough expiratory flow values are lower than actual values. ${ }^{14-16}$ Others have used differential pressure over a restricted orifice that was unable to record flows of less than $180 \mathrm{l} / \mathrm{min}$ which occurred in all polio patients, ${ }^{17}$ or wedge spirometry that failed to give information about cough expiratory volume and peak value time, ${ }^{18}$ or pneumotachographs that failed to record peak cough expiratory flow accurately with an overshoot noted in testing ${ }^{19}$ or were not linear in response over $375 \mathrm{1} / \mathrm{min}$ but were still used to give a mean cough expiratory flow rate for normal subjects of $487 \mathrm{l} / \mathrm{min} .^{20}$

The flow spikes seen on coughing in our study have been noted by other investigators using a pneumotachograph system ${ }^{19-22}$ or similar pressure transduction apparatus. ${ }^{17}$ The reduction or absence of flow spikes in subjects with RMW is consistent with findings when normal subjects were given d-tubocurarine to assess the effect of graded muscle weakness on peak cough expiratory flow. ${ }^{21}$ The transient cough expiratory flow spikes were diminished or abolished. Compression and subsequent expulsion of air from intrathoracic airways has been suggested as the cause of these transient cough spikes. ${ }^{23}$ This intrathoracic airway compression is related to the pleural pressure which is diminished with curarisation. ${ }^{21}$ The cough expiratory volume was also reduced as curarisation progressed in this study.

The peak cough expiratory flow in our study was greater than PEFR, which is in accordance with pneumotachographic studies where the same method was used to measure both ${ }^{18-20}$ but in contrast to a study using the Wright peak flow meter in which no difference was noted. ${ }^{14}$ Cough expiratory volume was recorded as the maximum expiratory volume recorded during a cough and its duration of $<1$ second can explain its reduction compared with $\mathrm{FEV}_{1}$ in normal subjects and those with RMW. Airflow obstruction in patients with COPD probably gave rise to their similar baseline cough expiratory volume and $\mathrm{FEV}_{1}$. 
In comparison with other studies the mean peak cough expiratory flow value obtained in our study was higher for our normal subjects and those with COPD and lower for our subjects with RMW without spinal abnormalities. The mean peak cough expiratory flow in normal, COPD, and RMW subjects in these pneumotachograph studies ranges from $465 \mathrm{l} /$ min to $5921 / \mathrm{min}$ for normal subjects, ${ }^{17} 2021$ from $165 \mathrm{l} / \mathrm{min}$ to $321 \mathrm{l} / \mathrm{min}$ for subjects with COPD, ${ }^{17}{ }^{20}$ and from $<180 \mathrm{l} / \mathrm{min}$ to $218 \mathrm{l} / \mathrm{min}$ in subjects with RMW. ${ }^{17}{ }^{18}$ The peak cough expiratory flow and cough expiratory volume have been shown to depend on lung function while the peak value time was independent of this. ${ }^{24}$ The peak value time has been shown to reflect upper airway function. The prolonged peak value time in patients with unilateral vocal cord palsy was significantly reduced by vocal cord augmentation. ${ }^{22}$ The prolonged peak value time in our RMW group without scoliosis may reflect either delayed opening of the vocal cords or a delay in obtaining pressures to generate flow. All the groups increased their peak value time with manually assisted cough and, since this is independent of lung function, it is probably due to the assisted cough technique itself. ${ }^{24}$ The peak value time has been shown also to be related to the timing of the maximum transpulmonary pressure (measured as the difference between oesophageal and mouth pressure) in normal subjects. ${ }^{20}$ Incoordination of the thoracoabdominal thrust and the voluntary cough during manually assisted cough could have delayed increasing oesophageal pressure until after the glottis has opened, thus delaying the onset of peak cough expiratory flow. Improved coordination may have been achieved by commencing a voluntary cough once a thoracoabdominal thrust had been initiated, rather than vice versa as in our study, and this could have given rise to an even greater peak cough expiratory flow in subjects with RMW.

Subjects with COPD did not benefit with regard either to cough flow dynamics or subjectively with assisted cough techniques. They had no expiratory muscle weakness and it was not surprising that there was no improvement with manually assisted cough, but the decrease in peak cough expiratory flow and cough expiratory volume was unexpected. Manually assisted cough may cause premature airway closure in the peripheries causing the reduced peak cough expiratory flow. Mechanical insufflation may exacerbate hyperinflation of the lung in patients with COPD, and this may contribute to the reduced cough expiratory volume seen. We did not perform a PEFR after each manoeuvre and bronchoconstriction cannot be excluded as contributing to the decrease in flow.

In contrast to our study, improvements in FVC, sputum expectoration, and cough flow dynamics have been reported with other assisted cough techniques including voluntary coughing, ${ }^{25}$ mechanical insufflationexsufflation, ${ }^{26}$ positive expiratory pressure, ${ }^{27}$ and intrapulmonary percussive ventilator. ${ }^{28}$ Voluntary coughing increases the clearance of radiolabelled mucus from patients with airways obstruction compared with controls, and no significant improvement over voluntary coughing was noted when the forced expiration technique was used..$^{25}$ Mechanical insufflationexsufflation differing from mechanical insufflation used in our study by the addition of negative pressure during coughing has been shown to improve radiolabelled suspension clearance from animal models, ${ }^{29}$ increase peak cough expiratory flow in subjects with airways obstruction, and improve radiological and clinical signs in acutely ill patients with airways obstruction. $^{26}$

Our RMW subjects without scoliosis increased their peak cough expiratory flow with all three assisted cough manoeuvres. The rise in peak cough expiratory flow with manually assisted cough was probably due to the increased intrathoracic pressure generated by thoracic and abdominal compression. Mechanical insufflation probably raised the lung volume before coughing and thereby raised the peak cough expiratory flow. The cough expiratory volume with mechanical insufflation produced a non-significant increase. The tailoring of insufflation pressures to each patient rather than applying a standard pressure for all subjects as we used may give better results.

The use of assisted cough techniques by carers has reduced the frequency of pulmonary complications caused by retained airways secretions. ${ }^{15}$ Improvements in cough dynamics in patients with RMW have been reported using the same or alternative techniques of cough assistance using mechanical insufflation-exsufflation, ${ }^{826}$ manually assisted cough, ${ }^{818}$ trunk compression with abdominal binder, ${ }^{30}{ }^{31}$ mechanical insufflation, ${ }^{18}$ and positive expiratory pressure. ${ }^{27}$ They either aid the inspiratory phase of coughing (mechanical insufflation, glossopharyngeal breathing), or the expiratory phase of coughing (manually assisted cough, trunk compression with thoracoabdominal binder), or both (mechanical insufflation-exsufflation).

The peak cough expiratory flow was significantly greater when manually assisted cough and mechanical insufflation were combined than when mechanical insufflation alone was used. This is similar to other studies in which techniques in combination were used to increase lung volume (breath stacking, glossopharyngeal and mechanical insufflation) and the expulsive phase of coughing (mechanical exsufflation)..$^{16}$ In one study in patients with RMW requiring ventilatory support, manually assisted cough accompanied by either breath stacking or glossopharyngeal breathing was similar to the median increase of $144 \mathrm{l} / \mathrm{min}$ in our study with manually assisted cough and mechanical insufflation together. The same study also showed that mechanical insufflationexsufflation improved peak cough expiratory flow to a greater extent than manually assisted cough with breath stacking or glossopharyngeal breathing. ${ }^{32}$

Our subjects with RMW with scoliosis failed to benefit from any of the techniques used in 
this study. The scoliosis made it difficult to locate the best position to place the hands for the generation of intrathoracic and intraabdominal pressure in manually assisted cough. A higher insufflatory pressure may have shown mechanical insufflation to be beneficial in these patients. Although they suffered from alveolar hypoventilation and required noninvasive ventilatory support, their PImax and Pemax were greater than those without scoliosis and this increased respiratory muscle strength probably contributed to the ineffectiveness of assisted cough techniques.

In conclusion, this prospective study confirms that manually assisted cough and mechanical insufflation alone or in combination improved the cough flow dynamics in those with RMW without scoliosis but not in those with scoliosis. In subjects with COPD all three assisted cough manoeuvres were detrimental to the cough flow dynamics and cannot be recommended for cough assistance. These techniques can be taught to carers and can reduce the frequency of pulmonary complications caused by retention of secretions. ${ }^{31}$ Mechanical insufflation should be tailored to the individual patient, taking into account the shape of the chest wall and adjusting the insufflation pressure to optimise its effectiveness.

1 Widdicombe JG. Physiology of cough. In: Braga PC, Allegra L, eds. Cough. New York: Raven Press, 1989:3-25.

2 Hardy KA. A review of airway clearance: new techniques, indications and recommendations. Respir Care 1994;39: 440-55.

3 Hanayama K, Ishikawa Y, Bach JR. Amyotrophic lateral sclerosis: successful treatment of mucous plugging by mechanical insufflation-exsufflation. Am f Phys Med Rehamechanical insufflation $1997 ; 76: 338-9$.

4 Bach JR, Alba AS, Bohatiuk G, et al. Mouth intermittent pressure ventilation in the management of postpolio respipressure ventilation in the management of
ratory insufficiency. Chest 1987;91:859-64.

5 Gracey DR, Divertie MB, Howard FM. Mechanical ventilation for respiratory failure in myasthenia gravis. Mayo Clin Proc 1983;58:597-602.

6 Bach JR. Pulmonary rehabilitation considerations for Duchenne muscular dystrophy: the prolongation of life by respiratory muscle aids. Crit Rev Phys Rehabilation Med 1992;3:239-69.

7 Bickerman HA, Itkin SE. The effect of a new bronchodilator aerosol on the air flow dynamics of the maximal voluntary cough of patients with broncial asthma and pulmonary empysema. 7 Chronic Dis 1958;8:629-36.

8 Bach JR. Update and perspective on noninvasive respiratory muscle aids. Part 2: Expiratory aids. Chest 1994;105:1538mus.
9 Hardy KA, Anderson BD. Noninvasive clearance of airway secretions. Respir Care Clin North Am 1996;2:323-45.

10 American Thoracic Society. Standards for the diagnosis and care of patients with chronic obstructive pulmonary disease (COPD) and asthma. Am Rev Respir Dis 1986;136:225-44.
Anon. Guidelines for the measurement of respiratory function. Respir Med 1994;88:165-94.

12 Wilson SH, Cooke NT, Edwards RHT, et al. Predicted normal values for maximal respiratory pressures in adults and childern. Thorax 1984;39:535-8.

13 Murty GE, Kelly PJ, Veale D. Tussometry and lung function. Clin Otolaryngol 1994;19:117-9.

14 Leiner GC, Abramowitz S, Small MJ, et al. Cough peak flow. Am f Med Sci 1966;251:211-4.

15 Bach JR, Smith WH, Micheals J, et al. Airways secretion clearance by mechanical exsufflation for post-poliomyelitis ventilator assisted individuals. Arch Phys Med Rehabil 1993; 74:170-7.

16 Bach JR. Amyotrophic lateral sclerosis: predictors for prolongation of life by noninvasive respiratory aids. Arch prolongation of life by noninvasive
Phys Med Rehabil 1995;76:828-32.

17 Barach AL, Beck GJ, Smith W. Mechanical production of expiratory flow surpassing the capacity of human coughing. Am F Med Sci 1953;226:241-8.

18 Kirby NA, Barnerias Mj, Siebens AA. An evaluation of assisted cough in quadriparetic patients. Arch Phys Med Rehabil 1966;47:705-10.

19 Loudon RG, Shaw GB. Mechanics of cough in normal subect and in patients with obstructive respiratory disease. $\mathrm{Am}$ Rev Respir Dis 1967;96:666-77.

20 Langlands J. The dynamics of cough in health and disease. Thorax 1967;22:88-96.

21 Arora NS, Gal TJ. Cough dynamics during progressive expiratory muscle weakness in healthy curarised subjects. $\mathcal{F}$ Appl Physiol 1981;51:494-8.

22 Murty GE, Kelly PJ, Bradley PJ. Tussometry: an objective assessment of vocal cord function. Ann Otol Rhino Laryngol 3;102:743-7.

23 Knudson RJ, Mead J, Knudson DE. Contribution of airway collapse to supramaximal expiratory flow. $\mathcal{F}$ Appl Physiol 1974;36:653-77.

24 Mahajan RP, Singh P, Murty GE, et al. Relationship between expired lung volume, peak flow rate and peak expiratory velocity time during a voluntary cough. $\mathrm{Br} f$ Anaesth 1994;72:298-301.

25 Hasani A, Pavia D, Agnew JE, et al. The effect of unproductive coughing/FET on regional mucus movement in the human lungs. Respir Med 1991;85(Suppl):23-6.

26 Barach AL, Beck GJ. Exsufflation with negative pressure: physiological and clinical studies in poliomyelitis, bronchial asthma, emphysema and bronchiectasis. Arch Intern Med 1954;93:825-41.

27 Mahlmeister MJ, Fink JB, Hoffman GL, et al. Positive expiratiry pressure mask therapy: theoretical and practical considerations and a review of the literature. Respir Care 1991; 36:1218-29.

28 McIntruff Sl, Shaw LI, Hodgkin JE, et al. Intrapulmonary percussive ventilation in the treatment of COPD. Respir Care 1985;30:885.

29 Bickerman HA. Exsufflation with negative pressure: elimination of radiopaque material and foreign bodies from bronchi of anesthetized dogs. Arch Intern Med 1954;93: 698-704.

30 Estenne M, Van Muylem A, Gorini M, et al. Effects on abdominal strapping in tetraplegic patients. Am $\mathcal{F}$ Respir Crit Care Med 1998;157:95-8.

31 Hill NS. Use of negative pressure ventilation, rocking beds and pneumobelts. Respir Care 1994;39:532-49.

32 Bach JR. Mechanical insufflation-exsufflation: comparison of peak expiratory flow with manually assisted and unassisted coughing techniques. Chest 1993;104:1553-62. 